\title{
A Statewide Professional Development Program for California Foreign Language Teachers
}

\author{
Albert S. Lozano \\ California State University, Sacramento
}

Amado M. Padilla

Stanford University

Hyekyung Sung

Stanford University

Duarte M. Silva

Stanford University

\begin{abstract}
The California Foreign Language Project (CFLP), established in 1988, is a voluntary professional development program designed to improve and expand elementary, secondary, and postsecondary foreign language teaching in California. CFLP consists of nine regional sites that work in conjunction with a central office to increase professional development for over 600 foreign language teachers annually. CFLP provides teacher participants with three major professional development services: (1) workshops provided by the regional sites, (2) partnerships with low-performing schools/districts, and (3) an annual Summer Leadership Seminar. Sites submit a portfolio at the end of each program year that allows them to demonstrate their effectiveness in meeting CFLP's goals. Evaluation results indicate that over a three-year period, the CFLP increased opportunities for participants to strengthen academic content knowledge and develop teacher leadership skills. Results also show that participants incorporated workshop materials in their sample lesson plans and their classroom teaching.
\end{abstract}

\section{Introduction}

Several reports on American education have argued that schools should increase the focus on foreign language education (President's Commission on Foreign Language and International Studies, 1979; Bush, 2001). The possible benefits of increasing American students' foreign language proficiency include an understanding of diverse cultures, improved economic effectiveness in dealing with international companies, and better national security (a sentiment that has increased since the events of September 11, 2001. One method of increasing American students' foreign language proficiency is to utilize professional development programs to increase the knowledge

Albert S. Lozano (PhD candidate, Stanford University) is Assistant Professor in the Bilingual/Multicultural Education Department at California State University, Sacramento.

Amado M. Padilla (PhD, University of New Mexico) is Professor of Psychological Studies in Education at Stanford University, Stanford, California.

Hyekyung Sung (PhD, Stanford University) is research associate at the School of Education, Stanford University, Stanford, California.

Duarte M. Silva (EdD, University of San Francisco) is the executive director of the California Foreign Language Project, School of Education, Stanford University, Stanford, California. 
of new and existing foreign language teachers. In 1988, state legislators established the California Subject Matter Projects (CSMPs)—professional development programs designed to assist California teachers in nine content areas (foreign language, history/social science, math, international studies, physical education/health, reading and literature, science, writing, and visual and performing arts). The California Foreign Language Project (CFLP) attempts to improve the professional knowledge of California foreign language teachers in proficiency-oriented instruction, and thereby increase student learning. The CFLP has nine regional sites that design professional development services to address six goals: (1) strengthen academic content knowledge, (2) develop teacher leadership, (3) provide service to low-performing schools and districts, (4) establish partnerships with low-performing schools, (5) establish and maintain a professional community and teacher networks, and (6) evaluate student learning.

This article will examine how the CFLP sites addressed the first two program goals: strengthen academic content knowledge and develop teacher leadership, over a threeyear period (from 1997-1998 through the 1999-2000 program years). Analysis will focus on the types of workshops the CFLP developed for teacher participants, as well as how they incorporated workshop materials into their teaching based on the examination of the sample lesson plans and videotapes of participants teaching in their classrooms. Each regional site collected information on their program activities and submitted this information to the CFLP central office at the end of each program year in a site portfolio. The CFLP, since the 1997-1998 program year, has been using the site portfolio as a formative evaluation device to inform respective sites on how well they addressed the CFLP's goals, as well as how sites could improve their program activities in subsequent years.

\section{Foreign Language Education}

The view of what constitutes solid foreign language pedagogy has changed over the past 30 years (National Board for Professional Teaching Standards, 2001; Omaggio Hadley, 2001). In the past, foreign language teachers-driven in part by the behaviorist paradigm that dominated education-typically used grammar translation and audiolingual methods in which students were passive learners. According to this model, instruction focused on teaching grammar rules and using memorization drills, with little or no emphasis on authentic communication. Today's foreign language teaching, referred to as "proficiency-oriented" or "communication-based" instruction, is student centered and aims to provide students with real-life competencies that facilitate genuine interaction, a paradigm shift supported by numerous foreign language researchers and associations (NCSSFL, 2002; Nebraska Department of Education, 1996; Phillips, 1991; Project ExCELL, 1997;
Pufahl, Rhodes, \& Christian, 2001; Strasheim, 1989). Omaggio Hadley (2001) wrote that proficiency-oriented instruction contains five principles. First, students must be allowed to practice using the language in a variety of contexts likely to be encountered in the target culture. Second, students must be given opportunities to practice carrying out a range of functions in the target language. Third, accuracy should be encouraged, accompanied by various forms of instruction and evaluative feedback. Fourth, instruction should address both students' affective and cognitive needs, as well as personal differences, preferences, and learning styles. Finally, proficiency-oriented instruction should include cultural understanding.

The shift toward using proficiency-oriented instruction has altered what is expected of foreign language teachers. It is important that foreign language teachers possess a high degree of linguistic proficiency in the target language (Barnes, 1996; Hammadou \& Bernhardt, 1987; Morain, 1993; Peyton, 1997; Phillips, 1991; Project ExCELL, 1997). Foreign language teachers must also possess content knowledge. Two influential guides to foreign language teachers in terms of content are the Standards for Foreign Language Learning: Preparing for the 21st Century and the follow-up document, Standards for Foreign Language Learning in the 21st Century (National Standards 1996, 1999). These documents outline five content standards or "5 Cs" (communication, cultures, connections, comparisons, and communities) that define what students should know and be able to do. Numerous states (e.g., Connecticut, Indiana, Nebraska, and Texas) have created their own version of the standards.

The goal of proficiency-oriented instruction is to help students acquire communicative competency in a foreign language. According to the world languages other than English standards, "Accomplished teachers design effective lessons that divide learning into manageable steps and consistently give students multiple opportunities to communicate in the target language" (National Board, 2001, p. 27). Effective foreign language teachers create and implement instructional sequences/lesson plans ${ }^{1}$ that engage students, create opportunities to use the target language in real-life and meaningful activities, and scaffold instruction so that input is comprehensible to the learners. In general, instructional sequences in foreign language consist of components such as: (1) setting the stage, (2) providing comprehensible input, (3) guided or independent practice, (4) evaluation, and (5) application and extension.

Technology can also be used to enhance foreign language instruction (Blake, 1997; Omaggio Hadley, 2001; Peyton, 1997; Project ExCELL, 1997; Pufahl et al., 2001). Although technology will not immediately make a classroom communication based, resources such as the Internet, the World Wide Web, or compact discs can enable teachers to provide students with glimpses of other cultures and 
communities that may not otherwise be possible (Blake, 1997). In sum, the CFLP focuses its primary attention on helping teacher participants strengthen their academic content knowledge necessary for proficiency-oriented instruction by helping them maintain their target language proficiency, understand the standards, design effective lesson plans, and incorporate technology into their teaching.

\section{Development of Teacher Leadership}

The CFLP's second goal is to provide classroom teachers with the skills necessary to be leaders in their profession. It is thus important that teacher participants be knowledgeable about educational reforms and issues that influence foreign language education. In addition, the CFLP encourages them to serve in leadership positions at the state and district levels, such as serving on a state-level curriculum commission, on textbook review/adoption committees, or as district education coordinators. The CFLP also wants participants to be positive influences in their schools. Not only must participants know what constitutes good foreign language pedagogy, they must also be able to disseminate this knowledge to their colleagues. Participants must thus learn strategies for working positively with other professional educators so they can move out of their own classrooms and assist their colleagues as master/cooperating teachers and mentors, and be able to serve on committees in decisionmaking positions.

\section{Professional Development}

Professional development has been identified as an integral part of educational reform (Guskey, 2000; Hawley \& Valli, 1999; Lewis, Parsad, Carey, Bartfai, Farris, \& Smerdon, 1999) and has been included in documents such as the Educational Excellence for All Children Act of 1999 (U.S. Department of Education, 1999) and No Child Left Behind (Bush, 2001). Lewis et al., (1999) wrote: "The inclusion of a national goal for teacher professional development represents an increased focus on professional development as an important vehicle for school reform and education excellence" (p. 21). State-sponsored professional development networks can provide participants with a variety of activities including curriculum workshops, leadership institutes, conferences, and other leadership opportunities. These teacher participants can then bring these new ideas back to their schools (Firestone \& Pennell, 1997; Lieberman \& McLaughlin, 1992). Educational researchers have argued that professional development should be a lifelong process (Guntermann, 1992; Peyton, 1997; Phillips, 1991; U.S. Department of Education, 1999). Moreover, current preservice teacher training may not provide foreign language teachers with all that is needed to be effective (Hammadou \& Bernhardt, 1987; Morain, 1993). Peyton (1997) added: "Regardless of the skills and knowledge that foreign language teachers possess when they commence teaching, maintenance and improvement must be an ongoing process" (p. 1). In sum, professional development for foreign language teachers should help them maintain proficiency in their target language, develop content knowledge, and learn what constitutes successful foreign language pedagogy (Project ExCELL, 1997; Sparks, 2002).

Guskey (2000) wrote that in order to assess a professional development program and its impact on participants, evaluation should occur on several levels that include: (1) participants' reactions to workshops or seminars, generally collected through surveys or follow-up phone interviews; (2) participants' learning, which may be measured by pre- and posttests, and participants' oral and/or written reflections; (3) gathering of information on organization and support change, (i.e., an analysis of how policies [at the federal, state, district, or schoollevel], resources, and/or leadership either support or impede professional development, using surveys, focus groups, direct observations, etc.); (4) participants' use of new knowledge and skills, which can be documented through classroom observations and videotapes; and (5) student learning outcomes, which can be measured by examining students' oral proficiency data or students' writing samples. Guskey stated that many professional development programs typically rely on "happiness" indicators-such as surveys given right after a workshop presentation-to judge how well participants liked the program while not seeking to address the issue of whether participants later used workshop materials in their classrooms, nor to assess if using workshop materials enhanced students' learning.

\section{Methodology}

\section{CFLP Evaluation Design}

The CFLP developed an evaluation design to collect information from regional sites about: (a) professional development activities, including sites' partnerships with low-performing schools²; (b) teacher implementation of strategies emphasized through CFLP professional development activities; and (c) student learning outcomes. This information is collected in a site portfolio, which regional sites submit to the CFLP central office at the end of each program year.

The first section of the portfolio concerning site performance contains program agendas, copies of handouts, materials used during program activities, and samples of written or technology-based materials created by participants during the programs offered. Participants evaluate each workshop using Likert-scale and open-ended questionnaires. Thus, the portfolio contains: (1) summaries of participant evaluations, both quantitative and qualitative, and (2) sites' responses to participants' workshop reactions. Sites also submit videotaped samples that are representative of their program activities. 
In the teacher performance section, regional sites provide: (1) sample lesson plans created by participants, and (2) videotapes (and accompanying lesson plans) of participants teaching in their own classrooms. The CFLP Evaluation Team developed a protocol to examine how well the lesson plans and videotaped classroom teaching samples reflect aspects of proficiency-oriented language instruction.

The student learning section is designed to examine how the teaching practices of participating teachers influence student outcomes. Each regional site selects at least two schools and assesses students' oral proficiency using the Stanford Foreign Language Oral Skills Evaluation Matrix (FLOSEM) (Padilla \& Sung, 1999). The Stanford FLOSEM assigns oral proficiency scores from 5 (very beginning level) to 30 (native-like proficiency). Proficiency ratings are collected twice a year (once after the first month of instruction and again at the end of the school year) from at least one classroom for each language level taught at the school.

Each year, sites submit a work plan to the CFLP central office that describes the types of workshops, conferences, and seminars they intend to develop that correspond to the CFLP's goals. After implementing these program activities, sites assemble a portfolio that best documents their program activities and their effects on teacher and student performance throughout the program year. Regional site evaluation teams are instructed on how to organize the site portfolios to include specific evidence that demonstrates each site's effectiveness in implementing their approved professional development program. Site portfolios are collected at the end of the program year and then analyzed by the CFLP evaluation staff. Sites receive a written feedback report based on the analyses of data provided in the site portfolio, including strategies for improving program activities and data collection for the following year. The report is given to the site directors, the evaluation liaison personnel, and other members of the site's leadership team. Thus, the site portfolio serves as a formative assessment tool that site leadership teams consider as they devise their following year's work-plan. Figure 1 is a model of the CFLP's evaluation design.

\section{CFLP Demographic Information}

Sites collect demographic information on all attendees after every CFLP event. In each of the three program years under discussion (1997-1998, 1998-1999, and 1999-2000), the CFLP provided professional development services for 600 to 700 participants. Almost $80 \%$ of the CFLP's participants were female. By ethnicity, Caucasians were the most represented group, annually comprising slightly more than $50 \%$ of participants. The second largest ethnic group was Hispanics, with 26\% in 1997-1998 and increasing to 31.4 $\%$ in 1999-2000. Almost 90\% of the CFLP participants were classroom teachers, with close to $70 \%$ teaching at the high school level, and the majority (65\%) teaching Spanish.

The demographic information indicates that more participants were attending CFLP professional development activities for longer periods of time. In the 1997-1998 and 1998-1999 program years, $17 \%$ of participants had participated in CFLP for more than four years. However, this percentage increased to $31.3 \%$ in 1999-2000.

Another important finding is that CFLP participants are becoming younger in terms of teaching experience, which may be a result of a modification of CFLP's goals. In 1998, California lawmakers passed legislation mandating that the CSMPs modify their professional development services to (a) incorporate standards-based education, and (b) increase services to low performing schools and districts. In 1997-1998, 50\% of participants had more than 10 years of teaching experience. Over the next two years this percentage decreased, to $45 \%$ in $1998-1999$ and to $42 \%$ in 1999-2000. The percentage of teachers with between 6 to 10 years of experience has stayed fairly consistent at around $20 \%$. However, the percentage of teachers with less than five years of teaching experience is increasing. In 1997-1998 and 1998-1999, 30\% of participants had less than five years of experience, a figure that increased to $36.1 \%$ in 1999-2000. The slight decrease in the percentage of participants with more than 10 years of experience, along with the increase in the percentage of participants with less than 5 years of experience, may be a reflection of the CFLP's focus on low-performing schools. DarlingHammond $(1995,2001)$ pointed out that poor schools and districts that are more likely to have low-performing schools generally employ teachers with less experience, reflected in the demographic changes of CFLP participants.

\section{Results}

\section{Site Performance}

Professional development workshop activities. Each year, the nine CFLP sites combined to provide over 170 days of professional development. Sites differed in how they grouped participants into tiers/strands due to differences in the number of participants, languages taught by participants, and years of experience both as foreign language teachers and with the CFLP. For instance, some sites had breakout sessions at each workshop designed specifically for new foreign language teachers, providing them with material pertinent to new teachers (e.g., classroom management), while providing leadership team members and veteran teachers with advanced-level presentations. Presentations also focused on the CFLP goals of strengthening academic content knowledge and providing opportunities for teacher leadership development.

To meet the goal of strengthening academic content knowledge, in 1997-1998 and 1998-1999, three sites constructed programs and activities to help participants increase and maintain their target language proficiency. 
Regional sites offered language enrichment programs in Spanish, French, Chinese, Japanese, and German. In the 1999-2000 program year, three more sites began providing participants with the opportunity to develop and maintain their target language proficiency. One site instituted a workshop series entitled "Improving Professional Literacy Skills Through World Languages." Participants attended five workshops in French or Spanish, were required to read novels, poems, and short stories in the respective language, and then completed assignments and discussed the works at site workshops. In the year-end portfolio, one regional official wrote that: "Many comments expressed a request for more time to be allotted to the language content strands in the 2000-2001 program year."

\section{Figure 1}

\section{CFLP EVALUATION MODEL}

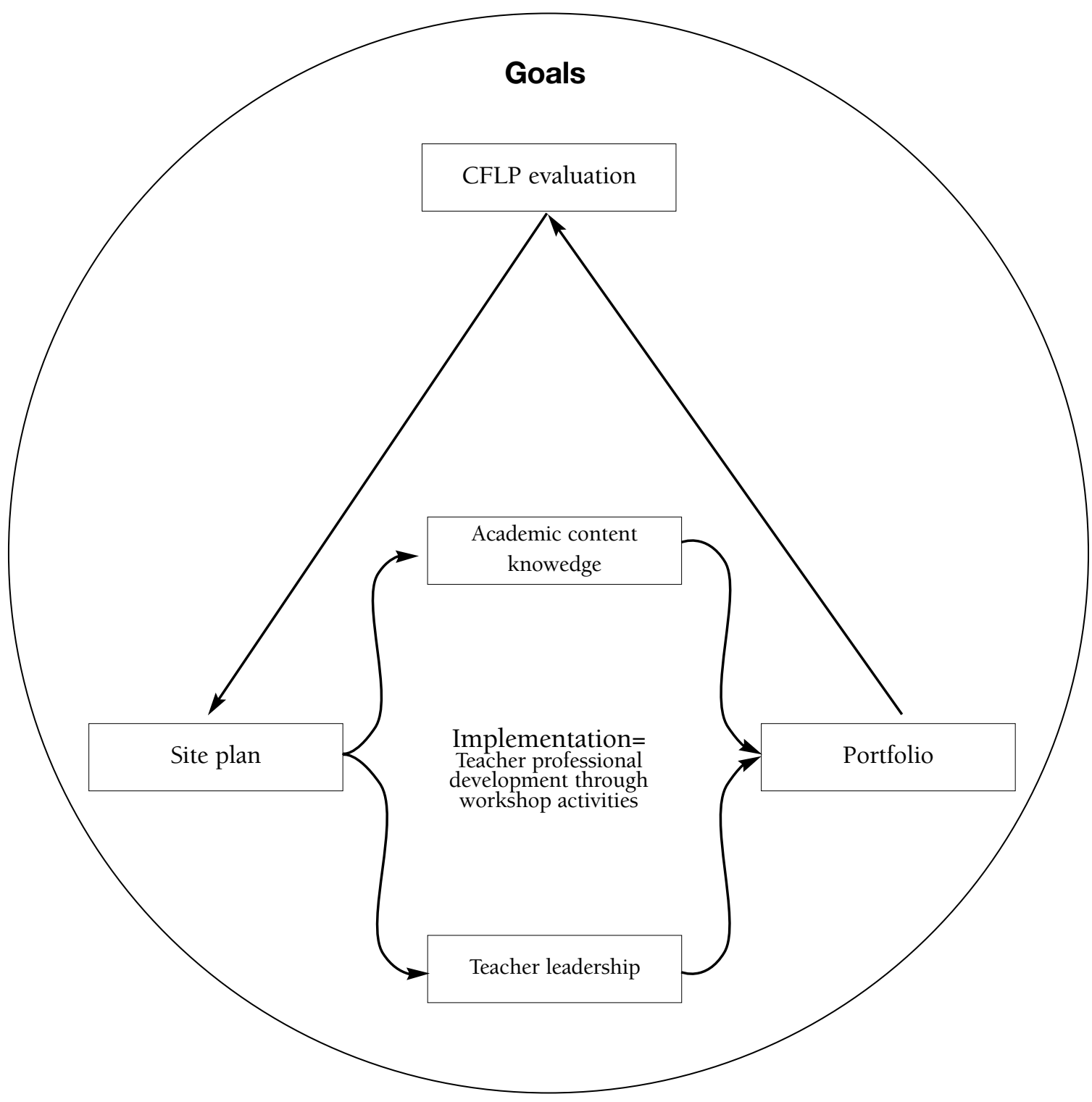


The goal of providing participants with instruction on incorporating the standards was met increasingly over the three-year period. In 1997-1998, only four sites introduced the standards into their program activities, yet in 1998-1999 and 1999-2000, every CFLP site incorporated the standards into their workshop activities. Sites varied in the way information about the standards was presented to participants. For example, some sites used the standards as the organizing principle for their professional development activities and provided all participants with information on the standards. Other sites provided instruction to particular strands over the course of one or two years, while one site focused on a particular standard (e.g., cultures) at each workshop during a program year. Participants appeared to appreciate learning about the standards as a tool for helping them increase their ability to deliver proficiency-oriented instruction. One participant wrote: "Everything was great. I enjoyed time to navigate the standards, process all the info, and start to see how it all connects with what I'm doing."

Planning, creating, and implementing an instructional sequence for foreign language instruction was a topic that also received more attention over the three-year period. In 1997-1998, three sites supplied participants with information on lesson planning, but by 1999-2000 every site explicitly addressed lesson planning and design. Sites also differed in how information on lesson plans was presented at site workshops. For instance, two sites presented instruction on lesson planning at specific workshops during the year to all participants, while a different site presented instruction to a single strand of participants for a two-year period. Regardless of the format, participants felt that workshop presentations were assisting them to prepare better lessons. One participant remarked: "I believe I am becoming a better teacher. I try to incorporate ideas ... into my own teaching, and I believe it's helped me to create better lessons and activities."

To enhance teachers' academic content knowledge, the CFLP sites also gave workshops on incorporating technology in foreign language education. One site developed two workshops on Web page building. A second site supported the Digital Stream language and technology conference at California State University, Monterey Bay, with many CFLP participants in attendance. A third site reintroduced technology into its program activities by creating an "e-mentoring" program, offered to all northern California foreign language teachers. Language teachers spoke with team members about professional issues, received advice on lesson planning, and took part in online discussions with colleagues.

Leadership development. The focus on providing participants with teacher leadership development, CFLP's second goal, fluctuated during the three-year period. In 1997-1998, five sites wrote in their annual reports that they provided leadership development for their partici- pants. A review of the site portfolios, however, indicated that these sites did not give participants the opportunity to present what they had learned at workshops and conferences, or mentor more inexperienced colleagues-activities consistent with a teacher leader.

To remedy this situation the following year, seven of the nine sites focused more explicitly on the goal of teacher leadership development. Several sites provided leadership and potential leadership team members with special summer sessions that included topics such as incorporating the standards into their lesson planning, developing effective strategies of direct instruction, and professional portfolio development. Sites also sponsored teachers at local conferences, a symposium on leadership development and a special workshop on the FLOSEM for leadership team members. One site conducted a two-day workshop for leadership team members on the standards and multiple intelligences, and one leadership team member stated: "The concepts were presented clearly. I will be mentoring teachers in San Francisco, and while I don't feel like an expert, your workshop has given me a degree of confidence I lacked before."

In 1999-2000, several sites incorporated special leadership development training into their workshop series. One site held a three-day summer institute devoted to standards for leadership team members, while a second site held a summer institute that examined topics such as standards-based instruction, the integration of technology, teaching diverse student populations, and professional networking. A leadership team member from this site stated: "I believe I am more professional, better prepared, and better able to handle situations that come up unexpectedly," while another added, "It has given me a stronger sense of my leadership capabilities." Other sites sponsored participants at local and national conferences or gave leadership team members the opportunity to mentor less-experienced participants. Finally, one site invited graduates of their program to present at site workshops, serve as mentors to new CFLP participants, and represent the site at regional conferences. Analysis of the site portfolios showed that the CFLP's efforts in teacher leadership improved throughout the three-year period.

\section{Teacher Performance}

In order to evaluate whether CFLP sites were accomplishing the goal of strengthening participants' academic content knowledge, various areas of teaching performance of the participants were analyzed.

Lesson plan samples. The lesson plans submitted in 1997-1998 represented a diverse array of languages and levels, from lessons designed for elementary students to those for university students in Spanish, French, German, Tagalong, Italian, and Swahili. For example, one lesson plan taught counting in Swahili to second graders, while 
another focused on teaching food names using realia to students in first-year Spanish. These lessons were both written in a five-step lesson format and described scenarios where students could engage in authentic communication, reflecting the CFLP's focus on proficiency-oriented instruction.

During the first year, many of the sites sporadically submitted lesson plans or used nonrepresentative samples. In 1998-1999, all nine sites presented information on the standards at their workshops and many of the 60 lesson plans that were submitted successfully integrated one of the five Cs. For example, one participant developed a French II lesson on creating a family photo album, in which students were required to make comparisons between family members while incorporating target grammar and vocabulary in writing and to present their photo albums orally. Participants' lesson plans were better developed than the previous program year, yet there was room for improvement in many areas. Several instructional sequences did not include one of the standards or failed to explicitly articulate which standard was incorporated in the lesson, and some did not address how students were evaluated.

In 1999-2000, regional sites increased their emphasis on instructional sequences. Over 80 lesson plans were submitted that reflected the diversity of languages and levels taught by participants. Analysis of the lesson plans showed evidence of improvement in the quality of the lesson plans. Lesson plans also contained material presented at site workshops. For instance, participants from the site that cosponsored the Digital Stream technology and language conference integrated technology into several proficiency-oriented lessons. Participants continued to create plans containing solid guided practice and comprehensible input activities but omitting application/extension activities and evaluation. One site leader wrote: "Although the participants appear to understand the design sequence, they were unable to develop lesson plans to fully develop the sequences. Noticeable by their absence were activities for application and extension." One teacher even said "N/A for application and extension! Evaluation is also an area of weakness."

Several sites, however, took steps to assist participants with preparing more effective lesson plans. For example, one site asked personnel and participants to critically reflect on each lesson plan, and lessons from this site specified which standard(s) was/were present, an element that participants had generally omitted in the past. Another site became more explicit in its instructions to participants, giving written instructions "to devise a Unit Plan that incorporates at least one 5-step lesson sequence (a lesson plan) and as many of the National Foreign Language Standards as possible." Moreover, this site's workshops included activities and assignments that specifically addressed the components of application/extension and evaluation. Finally, one regional site gave participants sev- eral assignments that included: (a) three drafts of the lesson plan; (b) a response to an article, "National Standards: How will you respond?"; (c) a response to the prompt, How the project has impacted my teaching; and (d) a reflection on target language usage.

Classroom teaching videotapes. Sites were asked to submit videotapes, with accompanying lesson plans, of at least two participants teaching in their own classrooms. In 1997-1998, a total of 14 participants were videotaped, but (1) video segments were not long enough (e.g., four minutes) to effectively evaluate the teaching, (2) sites did not include a corresponding lesson, or there was no indication on the lesson plan of the language level of the class; or (3) no videotapes were submitted. In addition, analysis of the videotapes indicated that in the majority of cases, participants had not yet become comfortable with proficiencyoriented instruction.

Sites submitted an equal number of videotapes in 1998-1999, yet the videotapes of participants teaching in their classrooms indicated that this sample of teachers was moving towards using more proficiency-oriented instruction. Participants created stronger corresponding lesson plans and demonstrated an increased ability to implement comprehensible input and guided practice activities. For example, an Arabic teacher of first graders used a variety of review and input strategies such as visuals, comprehension checks (e.g., yes/no questions), and playing "Simon says" in the target language. An Arabic teacher of a fourth/fifth grade combination class also used several comprehensible input devices and strategies, such as vocabulary cards and an identification game ("slap Jeopardy") while speaking only in Arabic. Videotapes revealed that many teachers, in particular those with less experience, had difficulty with classroom management and staying in the target language during explanations.

In 1999-2000, six of nine sites provided videotape samples of at least two participants in their classroom. Seventeen videotapes were submitted and the samples showed that participants used pedagogical practices discussed at site workshops. For example, one site submitted four videotapes and all four teachers continuously used comprehension checks and comprehensible input techniques. Several videotapes also included authentic studentto-student interaction, elements consistent with proficiency-oriented instruction. One area that did concern CFLP evaluators, however, was staying in the target language. Of the 17 videotape samples that were submitted, seven teachers did not stay in target language, with one teacher using English approximately 50\% of the time.

Analysis of the classroom teaching videotapes showed that teacher participants gradually incorporated what they had learned through CFLP professional development programs into their own teaching. It was also found that teach- 
ing experience may have been a factor in how well teachers maintained well-structured teaching and stayed in the target language in their teaching practices. In order to serve teachers with less experience, the CFLP's role in providing professional development programs in the profession appears to be critical.

\section{Discussion}

The ultimate goal of the CFLP's professional development program is to increase students' foreign language ability by improving teachers' academic content knowledge and proficiency-oriented instruction. An analysis of the programs provided by the regional sites and teacher performance data indicates that CFLP continuously created more opportunities for teacher participants to increase their academic content knowledge, the first of the CFLP's six goals, during three program years, 1997-1998 through 1999-2000.

The CFLP's professional development programs focused on common topics to develop participants' academic content knowledge. Hammadou and Bernhardt (1987) wrote that, "The most problematic area is the maintenance of language proficiency" (p. 305). Regional sites thus increased their emphasis on developing and maintaining participants' target language proficiency. By 1999-2000, six of nine sites had incorporated some forms of target language service. Moreover, all regional sites presented participants with information and instruction on the standards. Omaggio Hadley (2001) noted that the standards do not prescribe pedagogy or methodology but content, which is important for foreign language teachers to know.

Providing participants with instruction on creating and implementing an instructional sequence was also a topic that all nine sites had addressed by 1999-2000. Regional sites were asked to submit sample lesson plans and videotapes of participants teaching in their classrooms as part of the site portfolios. During the three-year period, both the quantity and quality of the sample lesson plans and videotapes increased. Sites increased their focus on helping teachers create more effective lesson plans and gave participants more support, which translated to stronger lessons as the years progressed. Several sites noticed that the emphasis on guided practice and comprehensible input that occurred at their professional development programs meant that other lesson plan elements (e.g., application/extension and evaluation) were included only occasionally. The CFLP's professional development model requires that all lesson plan elements be continuously emphasized. It is anticipated that with more knowledge and practice, participants will be able to construct lesson plans that incorporate all necessary steps.

Areas for improvement. Site portfolios were useful in documenting how sites met the goals of developing program activities and increasing teacher performance over a three-year period. However, portfolios also showed that the CFLP has specific areas that need enhancement, such as incorporating technology into the workshop series. Language educators have stated that foreign language instruction can be aided by technology and that technology should supplement, not supplant, proficiency-oriented instruction (Blake, 1997; Omaggio Hadley, 2001; Peyton, 1997; Project ExCELL, 1997; Pufahl et al., 2001).

Another area that must be improved is data collection. Sites collect videotapes and accompanying lesson plans of participants teaching in their classrooms to determine if participants are implementing proficiency-oriented instruction in their classrooms. The CFLP uses these items because site personnel are also full-time educators and thus unable to conduct classroom observations, and videotapes capture more than a mere lesson plan. Sites use a protocol developed by the CFLP evaluation team to inform participants about their pedagogical practices, as well as to determine if workshop material is being used in participants' classrooms.

Unfortunately, many teachers may have been uncomfortable with the idea of videotaping their lessons because some of the program material (e.g., standards) was relatively new; thus, they had not developed enough confidence for implementing workshop materials. In addition, participants may have felt that supplying the site with a videotape of their teaching was threatening to students and thereby decided against complying with a request to prepare a videotape. Regardless of the reason, sites must continue to encourage participants to submit videotapes of their teaching so that sites can determine if program material is being implemented in participants' classrooms and adjust workshop presentations accordingly.

The CFLP lists as its second goal the development of teacher leadership. Recently sites are beginning to give participants additional leadership training by encouraging them to present at conferences, to become more involved in site decisionmaking, and to mentor less-experienced participants. These participants are thus better prepared to positively influence the course of foreign language education at their respective schools, reflecting previous research on the positive aspects of teacher networks (Firestone \& Pennell, 1997; Lieberman \& McLaughlin, 1992).

The site portfolio has been shown to be an effective method of assessing how well sites are addressing the CFLP's goals. The portfolios also allow the CFLP staff to provide specific feedback to sites on meeting workshop objectives. What the site portfolio cannot do is assess the change in participants' practice as a result of the CFLP site activities. Measurement of the CFLP's performance at the individual level, therefore, is an area that both the central CFLP staff and site personnel should address in the future.

In spite of the need for improvement in the project in several areas, it nevertheless appears that participants did increase their knowledge of proficiency-oriented instruction, and that both new and veteran foreign language teachers benefited from their professional development experience. One participant stated: "Since I'm relatively 'new' in 
the Spanish teaching arena, I crave this knowledge. This is a new beginning for me and I cannot tell you how useful this is for me. Many thanks for the wonderful program."

\section{Notes}

1 The terms instructional sequence and lesson plan are used interchangeably.

2 The California Department of Education identifies a school as "low-performing" if scores on the Stanford Achievement TestVersion 9 (SAT-9) are in the bottom $40 \%$. CFLP uses a school's SAT-9 scores in English/Language Arts.

\section{References}

Barnes, A. (1996). Maintaining language skills in the initial training of foreign language teachers. Language Learning Journal, 14, 58-64.

Blake, J. (1997). The virtual global village: The World Wide Web, instructional technology and the "communicative" language classroom. In Mid-South Instructional Technology Conference Proceedings (2nd, Murfreesboro, TN, April 6-8, 1997). Retrieved from http://www.mtsu.edu/ itconf/proceed97/villagel.html

Bush, G. W. (2001). No child left behind. U.S. Department of Education, Office of the Secretary. Retrieved from http://www.ed.gov/pubs/edpubs/html

Darling-Hammond, L. (1995). Inequality and access to knowledge. In C. A. Banks \& C. A. McGee Banks (Eds.), Handbook of research on multicultural education (pp. 465-483). New York: Macmillan Publishing.

Darling-Hammond, L. (2001). The challenge of staffing our schools. Educational Leadership, 58(8), 12-17.

Firestone, W. A., \& Pennell, J. R. (1997). Designing state-sponsored teacher networks: A comparison of two cases. American Educational Research Journal, 34(2), 237-266.

Guntermann, G. (1992). Developing tomorrow's teachers of world language. ERIC Digest. Washington DC: ERIC Clearinghouse on Languages and Linguistics.

Guskey, T. (2000). Evaluating professional development. Thousand Oaks, CA: Corwin Press, Inc.

Hammadou, J., \& Bernhardt, E. B. (1987). On being and becoming a foreign language teacher. Theory into practice, 26(4), 301-306.

Hawley, W. D., \& Valli, L. (1999). The essentials of effective professional development: A new consensus. In L. DarlingHammond \& G. Sykes (Eds.), Teaching as the learning profession: Handbook of policy and practice. (pp. 127-150). San Francisco: Jossey-Bass Publishers.

Lewis, L., Parsad, B., Carey, N., Bartfai, N., Farris, E., \& Smerdon, B. (1999). Teacher quality: A report on the preparation and qualifications of public school teachers. Statistical analysis report. Washington, DC: National Center for Education Statistics. (ERIC Document Reproduction Service No. ED427009)

Lieberman, A., \& McLaughlin, M. W. (1992). Networks for educational change: Powerful and problematic. Phi Delta Kappan, 73, 673-677.
Morain, G. (1993). A view from the top of the tree. Canadian Modern Language Review, 50(1), 101-106.

National Board for Professional Teaching Standards (2001). World languages other than English standards (for teachers of students ages 3-18+). Retrieved from http://www.nbpts.org/pdf/ecya_wloe.pdf

National Council of State Supervisors of Foreign Languages (NCSSFL). (2002). A rationale for foreign language education: A position paper of the national council of state supervisors of foreign languages. Retrieved from http://www.ncssfl.org/rationale.htm

National Standards in Foreign Language Education Project. (1996). Standards for foreign language learning: Preparing for the 21st century. Yonkers, NY: Author.

National Standards in Foreign Language Education Project. (1999). Standards for foreign language learning in the 21st century. Yonkers, NY: Author.

Nebraska Department of Education. (1996). Nebraska K-12 foreign language frameworks. Lincoln, NE: Nebraska Department of Education.

Omaggio Hadley, A. (2001). Teaching language in context (3rd ed). Boston, MA: Heinle \& Heinle.

Padilla, A. M., \& Sung, H. (1999). The Stanford foreign language oral skills evaluation matrix (FLOSEM): A rating scale for assessing communicative proficiency. (ERIC Document Reproduction Service No. ED445538).

Peyton, J. K. (1997). Professional development of foreign language teachers. ERIC Digest. Washington, DC: ERIC Clearinghouse on Languages and Linguistics.

Phillips, J. T. (1991). Upgrading the target language proficiency levels of foreign language teachers. ERIC Digest. Washington, DC: ERIC Clearinghouse on Languages and Linguistics.

President's Commission on Foreign Language and International Studies. (1979). President's commission on foreign language and international studies: Background papers and studies. Washington, DC: U.S. Government Printing Office.

Project ExCELL (Excellence and Challenge: Expectations for Language Learners). (1997). Professional development for language teachers: Implementing the Texas essential knowledge and skills for languages other than English. Austin, TX: Southwest Educational Development Laboratory and Texas Education Agency.

Pufahl, I., Rhodes, N. C., \& Christian, D. (2001). What we can learn from foreign language teaching in other countries. ERIC Digest. Washington, DC: ERIC Clearinghouse on Languages and Linguistics.

Sparks, D. (2002). Designing powerful professional development of teachers and principals. National Staff Development Council. Retrieved from http://www.nsdc.org/sparksbook.html

Strasheim, L. A. (1989). Proficiency-oriented foreign language in the small high school. ERIC Digest. Charleston, WV: ERIC Clearinghouse on Rural Education and Small Schools.

U.S. Department of Education (1999). Educational excellence for all children act of 1999: An overview of the Clinton administration's proposal to reauthorize the elementary and secondary act of 1965. Washington DC: U.S. Government Printing Office. 